Erratum

Due to a printer's error reproduction of figs. 2a and $3 \mathrm{a}$ of the following paper, published in Volume 36(1996), pp. 87-93, was too dark. The correct version is printed below.

\title{
Selectivities in methanol oxidation over silica supported molybdena
}

\author{
Wu-Hsun Cheng \\ Chang Gung University, Chemical Engineering Department, Kweishan, Taoyuan, Taiwan, ROC
}

Received 13 June 1995; accepted 1 September 1995

\begin{abstract}
Selectivities in methanol oxidation over silica supported molybdenum oxide catalysts were investigated in relation with the phase distribution. The supported catalysts were prepared by impregnation with ammonium heptamolybdate. In addition to crystalline $\mathrm{MoO}_{3}, \mathrm{Mo}$ containing cluster species of 1-2 nm size were observed by STEM even from a used catalyst with $13 \%$ catalyst loading. The percentage of Mo present as crystalline $\mathrm{MoO}_{3}$ increases with the catalyst loading. An ESCA study indicates that part of surface Mo in the supported catalysts is reduced to $\mathrm{Mo}^{5+}$. The dimethyl ether selectivity increases with the catalyst loading and its formation occurs over the crystalline $\mathrm{MoO}_{3}$ phase. The selectivities to $\mathrm{CO}$ and methyl formate are greatly enhanced because of the presence of support, and are relatively independent of the catalyst loading and phase distribution. The dependence and independence of the selectivities of different byproducts on the loading make the silica supported catalysts with high catalyst loadings less selective for the partial oxidation of methanol to formaldehyde.
\end{abstract}

Keywords: methanol oxidation; silica; molybdenum oxide; $\mathrm{MoO}_{3}$; cluster; XRD; STEM; methanol; formaldehyde

\section{Introduction}

The partial oxidation of methanol to formaldehyde over bulk $\mathrm{MoO}_{3}$ based oxides is an important industrial reaction and has been studied extensively [1-6]. Use of supported molybdenum oxide catalysts for the methanol oxidation reaction was studied to increase the strength of the catalysts for the fluidized bed application. Supports studied include $\mathrm{SiO}_{2}$ [7-9], $\mathrm{Al}_{2} \mathrm{O}_{3}$ [10], $\mathrm{TiO}_{2}$ [11], $\mathrm{ZrO}_{2}[12]$ and $\mathrm{Fe}_{2} \mathrm{O}_{3}$ [13].

Unlike alumina support, silica only weakly interacts with molybdenum oxide. Depending on the method of preparation, various types of Mo species have been reported for silica supported catalysts. Impregnation with ammonium heptamolybdate generally yields low dispersions; crystalline $\mathrm{MoO}_{3}$ was found at Mo loading down to $0.4 \mathrm{wt} \%$ [14]. Preparation based on interaction between a silanol group and organometallic compounds such as $\mathrm{Mo}\left(\eta^{3}-\mathrm{C}_{3} \mathrm{H}_{5}\right)_{4}$ and $\mathrm{Mo}_{2}\left(\eta^{3}-\mathrm{C}_{3} \mathrm{H}_{5}\right)_{4}$ was reported to produce highly dispersed Mo species [15-17]. Polymolybdate, such as heptamolybdate, was identified by Raman spectroscopy for the hydrated state of the catalyst [15-17]. Upon dehydration by thermal heating, spreading of Mo species occurs and yields isolated $\mathrm{Mo}^{6+}$ species [18].

Many supported molybdenum oxide catalysts have lower selectivity to formaldehyde than the unsupported catalysts in methanol oxidation $[7,19,20]$. Yang et al. were even surprised to find that the selectivity to formaldehyde over silica supported molybdena catalysts decreases with the Moloading although the unsupported $\mathrm{MoO}_{3}$ is a very selective catalyst [7]. Although a significant amount of studies on the characterization and syn- thesis of silica supported molybdena catalysts have been conducted, there has been little study on the relation between phases in the supported catalysts and the selectivities in the oxidation of methanol despite of its scientific importance. We report here some selectivity issues over silica supported molybdenum oxide catalysts at high molybdenum loadings in combination with the characterization of Mo phases. This work reveals that the formation of dimethyl ether is phase dependent and occurs from the crystalline $\mathrm{MoO}_{3}$ phase. On the other hand, the formation of $\mathrm{CO}$ and methyl formate over the silica supported catalysts is phase independent.

\section{Experimental}

Bulk $\mathrm{MoO}_{3}$ was prepared by decomposing molybdenum oxalate obtained from Climax Molybdenum Company in $\mathrm{O}_{2}$ at $350^{\circ} \mathrm{C}$. It has an orthorhombic structure and surface area of $4.7 \mathrm{~m}^{2} / \mathrm{g}$. The silica supported Mo oxide catalysts were prepared by the impregnation technique using $\left(\mathrm{NH}_{4}\right)_{6} \mathrm{Mo}_{7} \mathrm{O}_{24} \cdot 4 \mathrm{H}_{2} \mathrm{O}$ as the $\mathrm{Mo}$ source. The silica support was obtained via Ludox ${ }^{\otimes}$ colloidal silica. The surface area of the support is $256 \mathrm{~m}^{2} / \mathrm{g}$. The catalysts were dried at $100^{\circ} \mathrm{C}$ for $16 \mathrm{~h}$ and calcined at $350^{\circ} \mathrm{C}$ for $1 \mathrm{~h}$ in $\mathrm{O}_{2} .2 \mathrm{~g}$ of catalysts were loaded in a fixed bed reactor ( $3 / 8^{\prime \prime}$ o.d. titanium). The catalysts were also conditioned at $350^{\circ} \mathrm{C}$ for $1 \mathrm{~h}$ in air everyday before the reaction study.

Methanol feed was introduced from a liquid pump and vaporized. The feed to the reactor contains $10 \%$ methanol in air at $75 \mathrm{sccm}$ (standard $\mathrm{cm}^{3} / \mathrm{min}$ ). These standard catalyst preparation and reaction conditions 
Table 1

Methanol oxidation over $\mathrm{MoO}_{3}, \mathrm{MoO}_{3} / \mathrm{SiO}_{2}$ and $\mathrm{SiO}_{2}$

\begin{tabular}{|c|c|c|c|c|c|c|c|c|}
\hline \multirow[t]{2}{*}{ Sample } & \multirow{2}{*}{$\begin{array}{l}\text { Reaction temp. } \\
\left({ }^{\circ} \mathrm{C}\right)\end{array}$} & \multirow{2}{*}{$\begin{array}{l}\text { Methanol conv. } \\
(\%)\end{array}$} & \multicolumn{6}{|c|}{ Selectivity ${ }^{a}(\%)$} \\
\hline & & & $\mathrm{CH}_{2} \mathrm{O}$ & DME & MF & methylal & $\mathrm{CO}$ & $\mathrm{CO}_{2}$ \\
\hline $\mathrm{MoO}_{3}$ & 300 & 49.8 & 78.5 & 12.4 & 4.2 & 3.0 & 1.8 & 0 \\
\hline $13 \% \mathrm{MoO}_{3} / \mathrm{SiO}_{2}{ }^{\mathrm{b}}$ & 300 & 94.6 & 67.2 & 8.4 & 2.0 & 0 & 21.2 & 1.3 \\
\hline $\mathrm{SiO}_{2}^{\mathrm{c}}$ & $\begin{array}{l}270 \\
300 \\
330\end{array}$ & $\begin{array}{r}6.5 \\
25.8 \\
34.3\end{array}$ & $\begin{array}{r}9.0 \\
16.4 \\
16.7\end{array}$ & $\begin{array}{l}0 \\
0 \\
0\end{array}$ & $\begin{array}{l}78.4 \\
42.5 \\
26.1\end{array}$ & $\begin{array}{l}0 \\
0 \\
0\end{array}$ & $\begin{array}{c}0 \\
11.5 \\
18.9\end{array}$ & $\begin{array}{l}12.7 \\
29.5 \\
38.3\end{array}$ \\
\hline
\end{tabular}

a DME: dimethyl ether, MF: methyl formate. ${ }^{\mathrm{b}}$ Feed was $7.1 \%$ methanol in air. $\quad{ }^{\mathrm{c}} 1.7 \mathrm{~g}$ of $\mathrm{SiO}_{2}$ was used.

were used unless otherwise indicated. The catalyst loading is expressed as a weight percent of $\mathrm{MoO}_{3}$. The selectivity is expressed as a mole percent. For convenience, the silica supported molybdenum oxides will be designated as $\mathrm{MoO}_{3} / \mathrm{SiO}_{2}$ in this paper.

The STEM study was conducted using a VG HB-501 STEM with a Kevex energy dispersive X-ray spectrometer. The specimen for the STEM study was prepared by grinding up the catalyst in a mortar and pestle and dispersing the dry particles on a carbon film. The IR study was performed using a Nicolet 3600 FTIR. XRD data were obtained from a Rigaku $\theta / \theta$ diffractometer using $\mathrm{Cu} \mathrm{K}_{\alpha}$ radiation. ESCA was performed with a Du Pont 650 equipment.

\section{Results}

\subsection{Methanol oxidation}

The methanol conversion and selectivities in metha- nol oxidation over a bulk $\mathrm{MoO}_{3}$, a silica supported $\mathrm{Mo}$ oxide and silica are shown in table 1. Dimethyl ether was observed from the bulk and supported molybdenum oxide catalysts but not from the support silica. Methyl formate is a major product from silica especially at low conversions. Interestingly, little $\mathrm{CO}_{2}$ is formed over the bulk and supported molybdenum oxide catalysts, but a significant amount of $\mathrm{CO}_{2}$ is produced from $\mathrm{SiO}_{2}$ although the activity of $\mathrm{SiO}_{2}$ is relatively low. The ratio of the $\mathrm{CO}_{2}$ selectivity to $\mathrm{CO}$ selectivity is high over $\mathrm{SiO}_{2}$. This indicates that most of the surfaces of the supported catalyst no longer possess the intrinsic property of the silica support. The contribution of the bare $\mathrm{SiO}_{2}$ surfaces to the activity of the supported catalysts is minimal.

Deep oxidation of methanol to $\mathrm{CO}$ results in a major loss of the formaldehyde selectivity in the partial oxidation of methanol over the silica supported catalyst at high conversions. However, the selectivities also strongly depend on the conversion. Fig. 1 compares the selectivity to $\mathrm{CO}$ over bulk and supported catalysts at

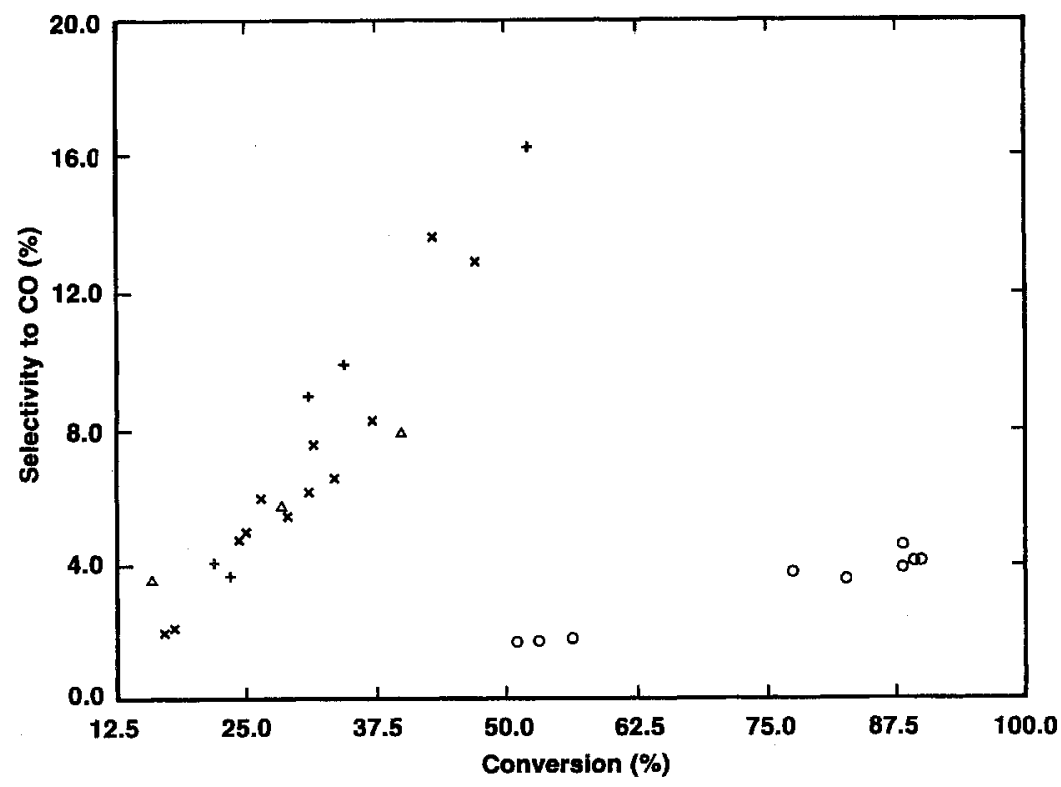

Fig. 1. The $\mathrm{CO}$ selectivity in methanol oxidation at various conversions over $9 \% \mathrm{MoO}_{3} / \mathrm{SiO}_{2}(\triangle), 13 \% \mathrm{MoO}_{3} / \mathrm{SiO}_{2}(+), 38 \% \mathrm{MoO}_{3} / \mathrm{SiO}_{2}(\times)$, and bulk $\mathrm{MoO}_{3}(\mathrm{O})$. 
various methanol conversions which were varied by changing reaction temperatures and methanol feed concentrations. The selectivity to $\mathrm{CO}$ over the supported catalysts is much higher than that from the bulk $\mathrm{MoO}_{3}$ catalyst at all conversion levels. However, there is no significant and consistent difference in the $\mathrm{CO}$ selectivity between the supported catalysts at different loadings.

The $13 \% \mathrm{MoO}_{3} / \mathrm{SiO}_{2}$ was studied further for the effect of the crystallite size of $\mathrm{MoO}_{3}$ on the selectivity. The crystallite size was varied by changing the calcina- tion time. The only crystalline phase indicated by XRD was orthorhombic $\mathrm{MoO}_{3}$. The average crystallite size of $\mathrm{MoO}_{3}$ determined by $\mathrm{X}$-ray line broadening technique was $9.7 \mathrm{~nm}$ after $13 \% \mathrm{MoO}_{3} / \mathrm{SiO}_{2}$ was calcined at $350^{\circ} \mathrm{C}$ for $1 \mathrm{~h}$. The crystallite size increased to $19.8 \mathrm{~nm}$ after calcination at $350^{\circ} \mathrm{C}$ for $15 \mathrm{~h}$. However, little difference in the dependence of the $\mathrm{CO}$ selectivity on the conversion was observed between these two supported catalysts with different $\mathrm{MoO}_{3}$ crystallite size. The $\mathrm{CO}$ selectivity is relatively independent of the catalyst loading as well as a

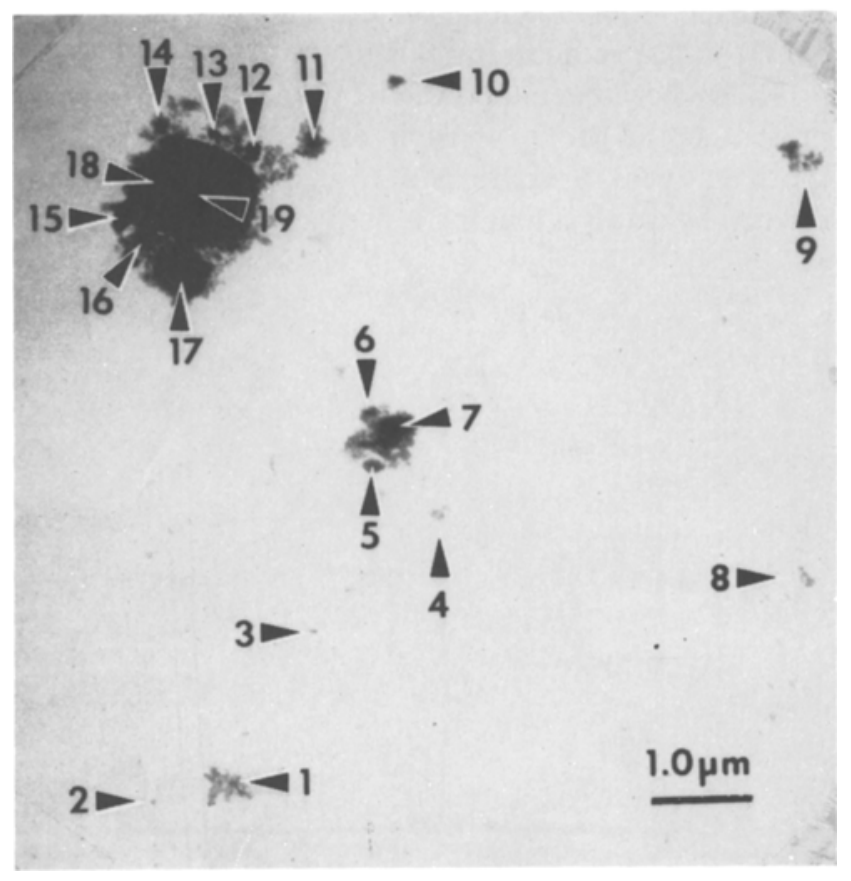

b

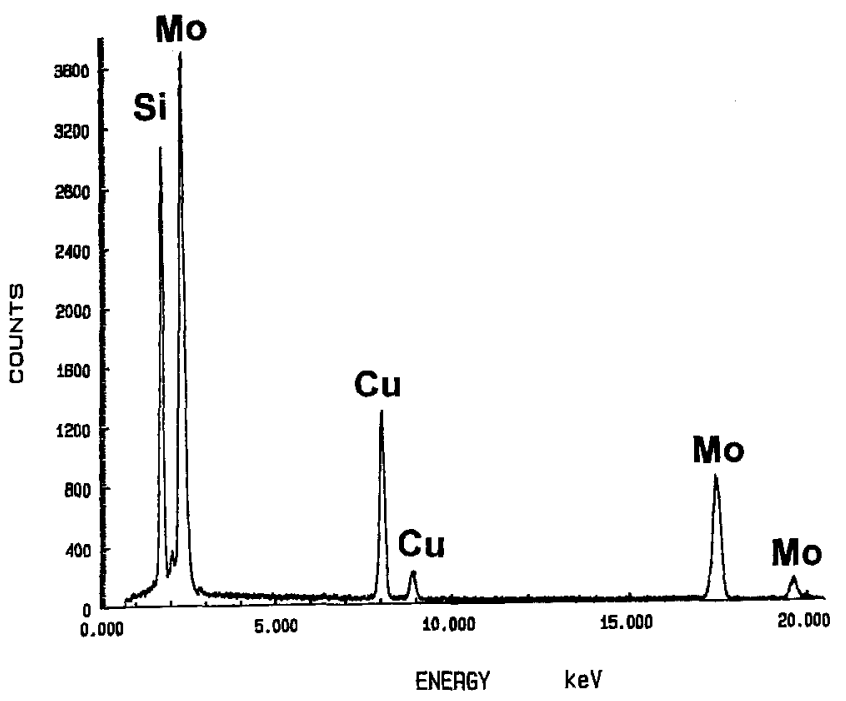

c

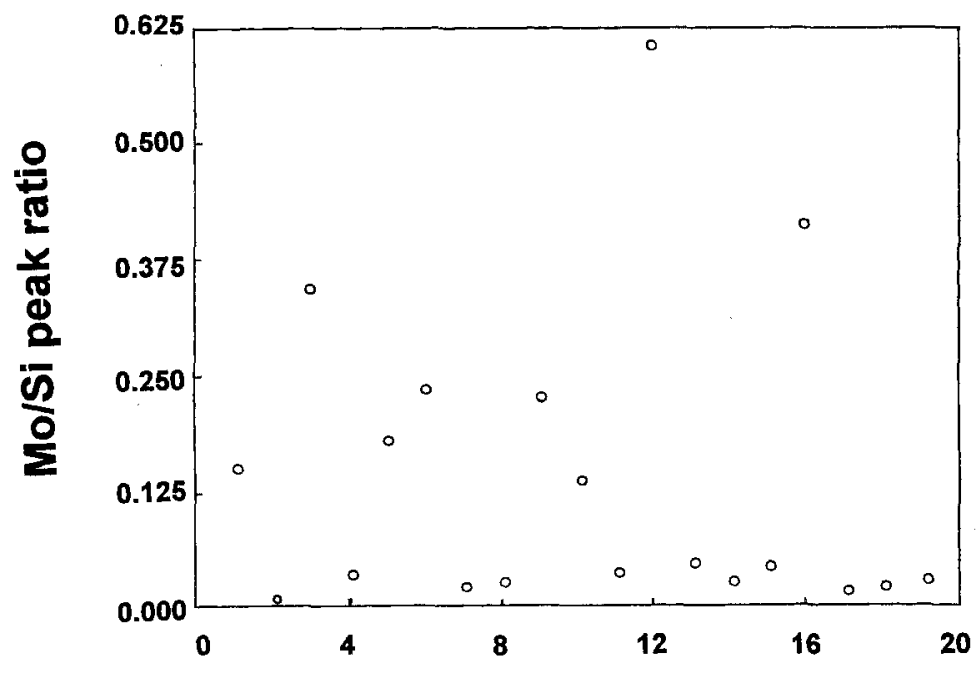

Spot number

Fig. 2. (a) Bright-field STEM survey image of the used $13 \% \mathrm{MoO}_{3} / \mathrm{SiO}_{2}$ specimen. (b) X-ray spectrum of spot 12 . (c) The intensity ratio of lowenergy Mo-to-Si peaks for the spots indicated on (a). 
the crystallite size of $\mathrm{MoO}_{3}$ for the silica supported catalysts, but the support greatly increases the selectivity to CO.

\subsection{Characterization of supported Mo oxides}

To study the morphology of the supported molybdenum oxide catalysts, a used $13 \% \mathrm{MoO}_{3} / \mathrm{SiO}_{2}$ catalyst previously calcined for $15 \mathrm{~h}$ before the reaction was investigated by STEM. Fig. 2a shows a bright field image for a survey analysis. X-ray analysis was conducted in the STEM equipment. As an example, the X-ray spectrum taken with the raster size of about $200 \mathrm{~nm}$ square area for dark spot \#12 is given in fig. $2 \mathrm{~b}$. Cu peaks in the spectrum were originated from a Cu grid used to support the carbon film. The intensity ratios of the $\mathbf{M o ~ K}_{\alpha}$ to Si $\mathrm{K}_{\alpha}$ peaks are shown in fig. $2 \mathrm{c}$ for the spots indicated on fig. 2a. The intensity ratio of Mo to Si varies over a wide range. The dark spots with high $\mathrm{Mo} / \mathrm{Si}$ ratios probably contain crystalline $\mathrm{MoO}_{3}$ as revealed by XRD indicated in the previous section. To avoid electron scattering and bremsstrahlung generation creating detectable Mo X-rays even in areas free of Mo, a $20 \mathrm{~nm}$ single well-separated Ludox ${ }^{\circledR}$ sphere was used for the further study under a high magnification as shown in fig. 3. Some dark spots of 1-2 $\mathrm{nm}$ size can be clearly visualized (fig. 3a). X-ray analysis from just the dark spot shows the presence of Mo by scanning a very small raster of $2 \mathrm{~nm}$ square area over the particle (fig. 3b). Very little Mo was found in the adjacent clear area (fig. 3c). The STEM and XRD results clearly show that at least two morphologically distinct phases are present in the silica supported molybdenum oxide catalyst: crystalline $\mathrm{MoO}_{3}$ and $\mathrm{Mo}$ containing clusters.

To further understand the relative percentage of Mo present as the $\mathrm{MoO}_{3}$ phase in each supported catalyst, the XRD peak area for $\mathrm{MoO}_{3}$ at $0.326 \mathrm{~nm} d$ spacing divided by catalyst loading is used as an indicator. Simi- a

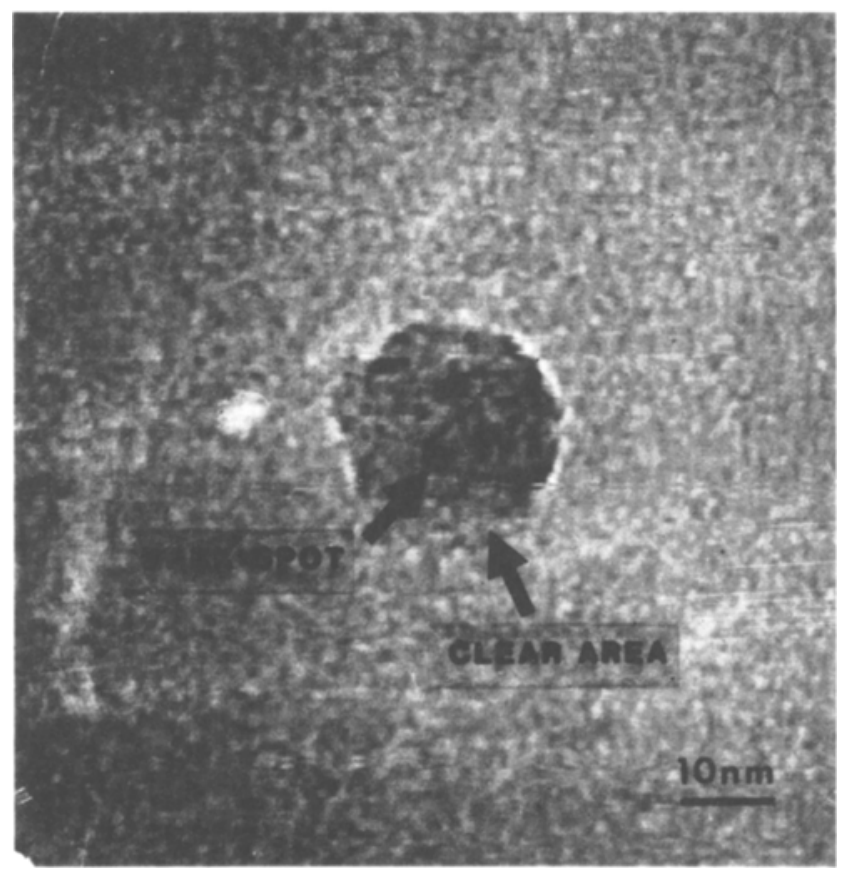

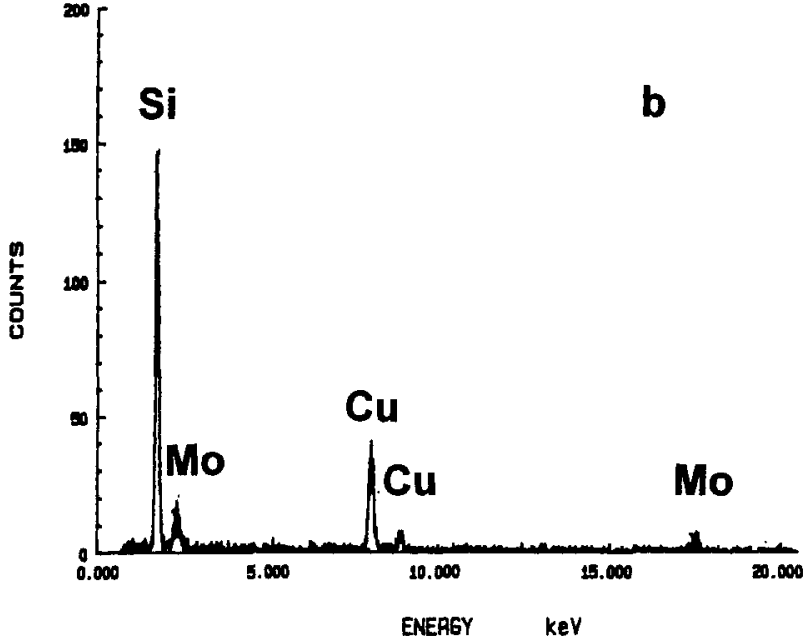

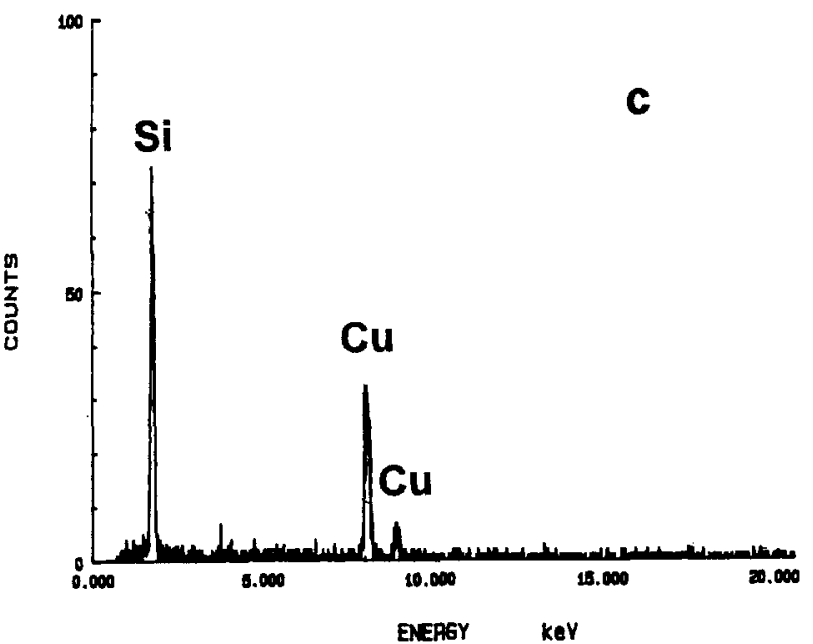

Fig. 3. (a) STEM image of a single Ludox sphere in the $13 \% \mathrm{MoO}_{3} / \mathrm{SiO}_{2}$ catalyst used showing dark spots of $1-2 \mathrm{~nm}$ size. (b) X-ray spectrum of the dark spot. (c) X-ray spectrum of the clear area. 
larly, the intensity of an IR peak for $\mathrm{MoO}_{3}$ at about $995 \mathrm{~cm}^{-1}$ with respect to the peak intensity at about $1170 \mathrm{~cm}^{-1}$ for $\mathrm{SiO}_{2}$ after loading adjustment is used as the second indicator. The results are given in table 2 . Each value was the average value of two repeated analyses. It can be drawn from these two studies that the relative composition of the $\mathrm{MoO}_{3}$ phase with respect to total Mo content generally increases with the Mo loading although the increase becomes slower at higher loadings.

ESCA was used to study the oxidation state of surface Mo in the bulk and supported molybdenum oxide catalysts. The ESCA spectrum of the fresh, bulk $\mathrm{MoO}_{3}$ catalyst shows the presence of $\mathrm{Mo}^{6+}$ only (fig. 4a). Its spectrum does not change after the reaction. However, the ESCA spectrum of the fresh $13 \% \mathrm{MoO}_{3} / \mathrm{SiO}_{2}$ catalyst shows the overlapping peaks of $\mathrm{Mo}^{6+}$ and $\mathrm{Mo}^{5+}$ (fig. 4b). Binding energy values were based on the Si $2 p$ peak of $\mathrm{SiO}_{2}$ at $103.5 \mathrm{eV}$ [21]. Binding energies of the $3 \mathrm{~d}$ doublets of $\mathrm{Mo}^{6+}$ and $\mathrm{Mo}^{5+}$ have been reported [22]. Part of surface Mo in the supported catalyst was in the reduced state. $\mathrm{Mo}^{5+}$ species still exists for the $13 \%$ $\mathrm{MoO}_{3} / \mathrm{SiO}_{2}$ catalyst calcined at $350^{\circ} \mathrm{C}$ for $15 \mathrm{~h}$.

\subsection{Relation of morphology with selectivities}

Although the selectivity to $\mathrm{CO}$ is relatively independent of the catalyst loading (fig. 1), the selectivity to dimethyl ether increases with the catalyst loading when compared at the same conversion. Fig. 5 gives an example at $40 \%$ conversion level. The selectivity to formaldehyde decreases with the catalyst loading because of the corresponding increase in the dimethyl ether selectivity. However, low selectivity to $\mathrm{CO}$ over the bulk $\mathrm{MoO}_{3}$ catalyst makes it a selective catalyst for the formaldehyde production. Similar dependence of the selectivities to $\mathrm{CO}$, dimethyl ether and formaldehyde on the catalyst loading was observed when comparisons were made at low conversions at the same $270^{\circ} \mathrm{C}$ (table 3 ). Similar to $\mathrm{CO}$, the selectivity to methyl formate is also relatively unaffected by the molybdenum loading; the selectivity is much higher over the supported catalysts than that from the bulk $\mathrm{MoO}_{3}$ catalyst. Table 3 also shows that the activities of these samples only vary within a limited range. From these results it can be

Table 2

Relative composition of the $\mathrm{MoO}_{3}$ phase indicated by XRD and IR

\begin{tabular}{lcc}
\hline Catalyst & XRD & IR \\
& $I_{\mathrm{MoO}_{3}} / L^{\mathrm{a}}$ & $\begin{array}{l}\left(I_{\left.\mathrm{MoO}_{3} / L\right)^{\mathrm{a}}}\right. \\
I_{\mathrm{SiO}_{2}} /(1-L)\end{array}$ \\
\hline $5 \% \mathrm{MoO}_{3} / \mathrm{SiO}_{2}$ & 18 & - \\
$9 \% \mathrm{MoO}_{3} / \mathrm{SiO}_{2}$ & 36 & 48 \\
$13 \% \mathrm{MoO}_{3} / \mathrm{SiO}_{2}$ & 100 & 100 \\
$38 \% \mathrm{MoO}_{3} / \mathrm{SiO}_{2}$ & 95 & 125
\end{tabular}

a Normalized with respect to $13 \% \mathrm{MoO}_{3} / \mathrm{SiO}_{2}$ at $100 ; L=\mathrm{MoO}_{3}$ loading.

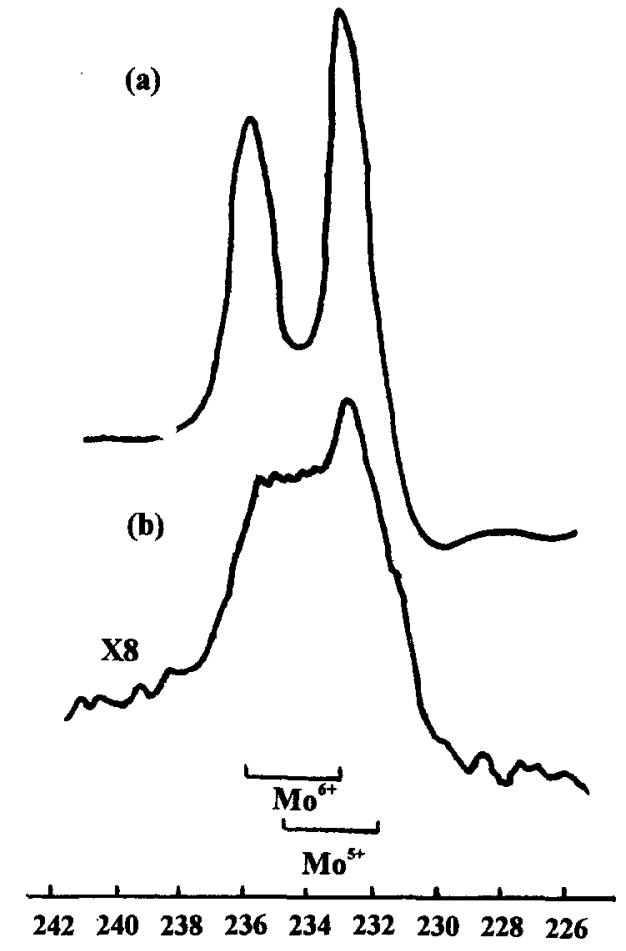

\section{Binding energy (ev)}

Fig. 4. (a) ESCA spectrum of the bulk $\mathrm{MoO}_{3}$ catalyst. (b) ESCA spectrum of the $13 \% \mathrm{MoO}_{3} / \mathrm{SiO}_{2}$ catalyst.

deduced that the dimethyl ether selectivity parallels with the relative composition of $\mathrm{MoO}_{3}$. The selectivity is also highest for the bulk $\mathrm{MoO}_{3}$ catalyst.

\section{Discussion}

The activity of silica in methanol oxidation is relatively low and its deep oxidation yields mainly $\mathrm{CO}_{2}$ instead of $\mathrm{CO}$. Contribution of the $\mathrm{SiO}_{2}$ surface to the formation of $\mathrm{CO}$ from the supported catalysts would be low. On the other hand, if we assume that $\mathrm{CO}_{2}$ is produced only from the $\mathrm{SiO}_{2}$ surface for the supported catalysts, the percentage of the bare $\mathrm{SiO}_{2}$ surface can be calculated by comparing the production of $\mathrm{CO}_{2}$ from the supported catalysts and the $\mathrm{CO}_{2}$ activity of silica. The result shows that less than $20 \%$ of the support surface of $13 \% \mathrm{MoO}_{3} / \mathrm{SiO}_{2}$ is intrinsic $\mathrm{SiO}_{2}$. Most of the $\mathrm{SiO}_{2}$ surface is covered or modified by molybdenum.

At least two morphologically distinct phases, crystalline $\mathrm{MoO}_{3}$ and cluster, were evidenced in the silica supported catalysts. XRD shows the presence of crystalline $\mathrm{MoO}_{3}$; STEM analysis reveals the presence of Mo containing, small clusters of 1-2 nm size. Furthermore, the normalized IR and XRD intensities for the $\mathrm{MoO}_{3}$ phase per unit loading vary with the catalyst loading. It suggests that more than one phase is present in the sup- 


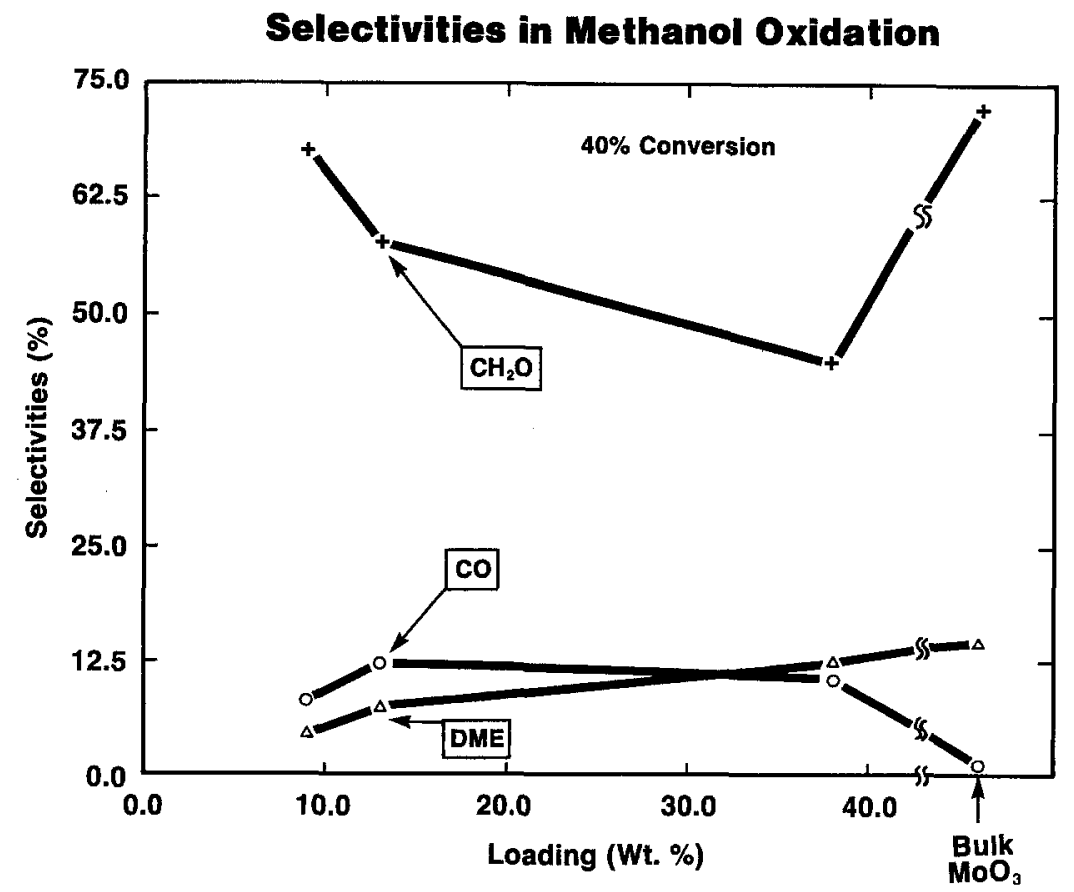

Fig. 5. Dependence of selectivities in methanol oxidation on catalyst loading at a constant $40 \%$ conversion.

ported catalysts. These results are consistent with Raman studies from similar impregnated catalysts showing $\mathrm{MoO}_{3}$ and the polymolybdate (i.e. heptamolybdate) cluster when the catalyst was in the hydrated state (e.g. in ambient environment) [16,17]. Heating the catalyst during the calcination converts polymolybdate to an isolated monodispersed $\mathrm{Mo}^{6+}$ species [18]. The polymolybdate cluster is reformed after rehydration. The spreading phenomenon on silica suggests that monodispersed Mo would also be present during the methanol oxidation reaction. Although the monodispersed Mo species was not directly observed in this study, its presence is consistent with the observation that bare $\mathrm{SiO}_{2}$ surface in the supported catalysts is very limited.

The IR and XRD study indicates that the composition of Mo present as crystalline $\mathrm{MoO}_{3}$ increases with the catalyst loading (table 2). It is clear from this study that dimethyl ether is largely produced from the $\mathrm{MoO}_{3}$ phase based on the direct correlation between the phase composition and the dimethyl ether selectivity. Since the selectivities in methanol oxidation strongly depend on the methanol conversion, the comparison was made at the same or similar conversion levels. This correlation indicates the dehydration activity of acidic $\mathrm{MoO}_{3}$. The selectivities to $\mathrm{CO}$ and methyl formate from the supported catalysts are much higher than those from the bulk $\mathrm{MoO}_{3}$ catalyst. It implies that these two products are largely produced from the dispersed species in the supported catalysts. Williams and Ekerdt recently reported that impurities on silica support, rather than the method of preparation or precursor, influence the selectivity (mainly methyl formate, formaldehyde and $\mathrm{CO}_{2}$ ) in methanol oxidation at low conversions for loading less than $1.1 \mathrm{wt} \%$ Mo metal [9]. The absence of the precursor effect suggests that the phases of Mo species would not affect the selectivity at low catalyst loadings. Our results extend the absence of the effect of Mo phases to high Mo loadings for the $\mathrm{CO}$ and methyl formate selectivities. The dimethyl ether selectivity was not addressed in Williams' study. Also contrary to their study, $\mathrm{CO}$ instead of $\mathrm{CO}_{2}$ was produced significantly from the supported catalysts. High ratios of $\mathrm{CO}$ to $\mathrm{CO}_{2}$

Table 3

Activity and selectivities in methanol oxidation at $270^{\circ} \mathrm{C}$

\begin{tabular}{|c|c|c|c|c|c|c|}
\hline \multirow[t]{2}{*}{ Catalyst } & \multirow{2}{*}{$\begin{array}{l}\text { Activity } \\
(\mathrm{mmol} /(\mathrm{h} \text { g-sample) })\end{array}$} & \multicolumn{5}{|c|}{ Selectivity $(\%)$} \\
\hline & & $\mathrm{CO}$ & DME & MF & methylal & $\mathrm{CH}_{2} \mathrm{O}$ \\
\hline $9 \% \mathrm{MoO}_{3} / \mathrm{SiO}_{2}$ & 1.53 & 3.7 & $\sim 0$ & 28.5 & 14.0 & 53.8 \\
\hline $13 \% \mathrm{MoO}_{3} / \mathrm{SiO}_{2}$ & 2.18 & 3.6 & 9.7 & 34.9 & 11.2 & 40.6 \\
\hline $38 \% \mathrm{MoO}_{3} / \mathrm{SiO}_{2}$ & 1.77 & 3.7 & 16.0 & 34.4 & 11.1 & 34.8 \\
\hline bulk $\mathrm{MoO}_{3}$ & 2.01 & $\sim 0$ & 16.6 & 4.6 & 15.6 & 63.2 \\
\hline
\end{tabular}


selectivities were also found from the unsupported catalyst from this study and others [3].

The selectivity to formaldehyde decreases with the catalyst loading although the unsupported $\mathrm{MoO}_{3}$ is a highly selective catalyst. This result confirms the early observation by Yang and Lunsford [7]. Our study further points out that the supported molybdenum oxide catalysts with high loadings are not very selective for the partial oxidation reaction because of high selectivities to $\mathrm{CO}$ and methyl formate due to the support effect and high dimethyl ether selectivity due to high compositions of the crystalline $\mathrm{MoO}_{3}$ phase. It also suggests that the formation of formaldehyde from the $\mathrm{MoO}_{3}$ phase in the supported catalysts does not occur as much as in the case when the support would not have been present. There are two possibilities for this: (1) formaldehyde produced is further oxidized to $\mathrm{CO}$ by dispersed species. This possibility is less likely because our separate study showed that the loss of the selectivity to formaldehyde over the supported catalysts is largely attributed to the deep oxidation of methanol rather than further oxidation of the product formaldehyde after it is produced in the gas phase [23]. (2) The production of formaldehyde is retarded over the $\mathrm{MoO}_{3}$ phase when the support is present. It has been shown that $\mathbf{C}-\mathbf{H}$ bond breaking is the slowest step in the production of formaldehyde over the bulk catalyst, and lattice oxygen is involved in the formaldehyde production process [2]. Fully oxidized $\mathrm{MoO}_{3}$ is most selective [6]. Pulse experiments show that formaldehyde selectivity decreases when a bulk $\mathrm{MoO}_{3}$ based catalyst is reduced [6]. Furthermore, the ESCA result in this study indicates that surface Mo in the supported catalyst tends to be reduced. Although our ESCA study cannot distinguish whether the reduction occurs only in the dispersed species or also in the crystalline $\mathrm{MoO}_{3}$ phase, the reaction study implies that the support may also facilitate the reduction of $\mathrm{MoO}_{3}$ and hence retard the production of formaldehyde.

\section{Acknowledgement}

The author would like to thank C. Lyman for STEM analysis. Part of the work was done at DuPont Company and is hereby acknowledged.

\section{References}

[1] J.M. Tatibouet and J.E. Germain, J. Catal. 72(1981) 375.

[2] C.J. Machiels and A.W. Sleight, in: Proc. 4th Int. Conf. on Chemistry and Uses of Molybdenum, 1982, eds. H.F. Barry and P.C.H. Mitchell (Climax Molybdenum Co., Ann Arbor, 1982) p. 411.

[3] W.H. Cheng, U. Chowdhry, A. Ferretti, L.E. Firment, R.P. Groff, C.J. Machiels, E.M. McCarron, F. Ohuchi, R.H. Staley and A.W. Sleight, in: Heterogeneous Catalysis, ed. B.L. Shapiro (Texas A \& M Univ. Press, College Station, 1984) pp. $165-181$.

[4] D. Klissurski, V. Rives, Y. Pesheva, I. Mitov and N. Abadzhjieva, Catal. Lett. 18(1993) 265.

[5] M. delArco, C. Martin, V. Rives, A.M. Estevez, M.C. Marquez and A.F. Tena, Mater. Chem. Phys. 23 (1989) 517.

[6] C.J. Machiels, W.H. Cheng, U. Chowdhry, L.E. Firment, F. Hong, E. McCarron, F. Ohuchi, R. Staley and A.W. Sleight, Appl. Catal. 25 (1986) 249.

[7] T.J. Yang and J.H. Lunsford, J. Catal. 103 (1987) 55.

[8] M. Carbucicchio and F. Trifirò, J. Catal. 62 (1980) 13.

[9] C.C. Williams and J.G. Ekerdt, J. Catal. 141 (1993) 430.

[10] M. Carbucicchio, F. Trifirò and A. Vaccari, J. Catal. 75 (1982) 207.

[11] K. Bruckman, B. Grzybowska, M. Che and J.M. Tatibouet, Appl. Catal. A 96(1993) 279.

[12] T. Ono, H. Miyata and Y. Kubokawa, J. Chem. Soc. Faraday Trans. I 83 (1987) 1761.

[13] H. Yamada, M. Niwa and Y. Murakami, Appl. Catal. A 96 (1993) 113

[14] S.R. Stampfl, Y. Chen, J.A. Dumesic, C. Niu and C.G. Hill Jr, J. Catal. 105 (1987) 445.

[15] C.C. Williams, J.G. Ekerdt, J.M. Jehng, F.D. Hardcastle, A.M. Turek and I.E. Wachs, J. Phys. Chem. 95(1991) 8781.

[16] R.D. Roark, S.D. Kohler and J.G. Ekerdt, Catal. Lett. 16 (1992) 71.

[17] R.D. Roark, S.D. Kohler, J.G. Ekerdt, D.S. Kim and I.E. Wachs, Catal. Lett. 16(1992) 77.

[18] M. de Boer, A.J. van Dillen, D.C. Koningsberger, J.W. Geus, M.A. Vuurman and I.E. Wachs, Catal. Lett. 11 (1991) 227.

[19] P. Forzatti, React. Kinet. Catal. Lett. 20 (1982) 213.

[20] C. Louis, J.M. Tatibouet and M. Che, J. Catal. 109 (1988) 354.

[21] T. Suzuki, S. Hayashi, T. Hirai, K. Tanaka and I. Toyoshima, React. Kinet. Catal. Lett. 40(1989) 1.

[22] M.B. Ward, M. J. Lin and J. H. Lunsford, J. Catal. 50 (1977) 306.

[23] W.H. Cheng, J. Catal., submitted. 